\title{
ResearchOnline@JCU
}

This is the author-created version of the following work:

Lowrie, Daniel, Ray, Robin, Plummer, David, and Yau, Matthew (2021)

Alignment and mismatch in role relations at end-of-life: a constructivist grounded theory study. Death Studies, 45 (5) pp. 361-370.

Access to this file is available from:

https://researchonline.jcu.edu.au/59774/

Accepted Version may be made open access in an Institutional Repository without embargo.

Please refer to the original source for the final version of this work: 


\section{Alignment and mismatch in role relations at end-of-life. A constructivist grounded theory study.}

Daniel Lowrie $\quad$ BHSc (OT), MSc

Lecturer and PhD Candidate. College of Healthcare Sciences, James Cook University, Townsville, Australia.

Robin A. Ray $\quad$ BEd, MHSc, $\mathrm{PhD}$

Associate Dean, Research Education. College of Medicine and Dentistry, Anton Breinl Research Centre for Health Systems Strengthening. James Cook University, Townsville, Australia.

David Plummer $\quad$ AM, MB, BS, PhD

Adjunct Professor. College of Medicine and Dentistry, James Cook University, Townsville, Australia.

Matthew Yau BAppSc, MCom, MSc (Hons), PhD, OTR, CST

Head and Professor. Department of Rehabilitation and Social Sciences, Tung Wah College, Kowloon, Hong Kong.

First published (online) $-9^{\text {th }}$ August 2019

Death Studies, [online] 1-10 DOI: 10.1080/07481187.2019.1648330 


\begin{abstract}
In this Australian, constructivist grounded theory study, we undertook in-depth interviews with 11 dying people and 8 caregivers to examine their perspectives on role relations at endof-life. We found that situations of role alignment between dying people and their family and friends support positive relational and practical outcomes, whereas role mismatch can cause considerable distress. Factors contributing to role mismatch at end-of-life were: dying people and their caregivers' efforts to shield each other from emotional harm; fear of social exclusion; and unwanted focus on the dying identity. Our findings highlight a need for flexibility and adaptability in end-of-life role relations.
\end{abstract}

\title{
Key words
}

- Dying

- Dying roles

- Role relations

- Palliative care 


\section{Alignment and Mismatch in Role Relations at End-of-life: A Constructivist Grounded Theory Study}

Dying roles serve an important function in guiding the enactment of key practical, personal and relational tasks during the end-of-life period (Emanuel, Bennett, \& Richardson, 2007). Like all social roles, dying roles are not fixed entities, occurring instead as a negotiated process between individuals (Biddle, 1986). This means that different actors play an active role in shaping role relations (Lynch, 2007). Understanding the relational nature of dying roles is of particular importance in palliative and end-of-life care. Dying persons continue to exist within a network of socially reciprocal relationships; therefore, dying unfolds as a collective experience among dying persons and their loved ones rather than as a solitary affair (Broom \& Kirby, 2013; Kellehear, 2008; Scarre, 2009). With this in mind, the dying process can be understood as bringing to the forefront complex needs, wishes, and agendas not only for dying people but also for members of their social networks (Broom \& Kirby, 2013; Kellehear, 2008).

Relationships between dying people and their friends and family are known to have a profound influence on the experiences of dying and end-of-life care (Broom \& Kirby, 2013; Kellehear, 2008). It is well established that families and non-kin caregivers frequently provide considerable assistance to dying people in the form of emotional support, help with decision-making, and provision of ongoing care at home (Burns, Abernethy, Leblanc, \& Currow, 2011; Clemmer, Ward-Griffin, \& Forbes, 2008; Hudson \& Payne, 2011; Kirby, Broom, Good, Wootton, \& Adams, 2014; Laryionava et al., 2018; Pleschberger \& Wosko, 2017). Research, however, also indicates that in many instances families and/or non-kin caregivers feel ill-equipped to negotiate the numerous and challenging relational and practical processes that accompany dying (Hudson \& Payne, 2011; Pleschberger \& Wosko, 2017). This state of affairs can result in a variety of difficulties such as psychological distress, 
feelings of resentment, social isolation, and financial strain, all of which can impact negatively on caregivers' health (Aoun, Kristjanson, Currow, \& Hudson, 2005; Hudson \& Payne, 2011; Laryionava et al., 2018).

The specific influence of roles and/or role relations as potential sources of difficulty at end-of life have been described in a few papers. Research undertaken by Clemmer et al. (2008) and, more recently Stone, Mikucki-Enyart, Middleton, Caughlin, and Brown (2012) point to the challenges associated with the juggling of multiple (and, at times, contradictory) roles among family caregivers of the dying person, highlighting feelings of powerlessness, uncertainty, confusion, isolation, and strain that can result. Other authors have suggested that conflict within the negotiated process of role transitions at end-of-life can occur when one party seeks to commence dying role relations while the other is not yet emotionally ready (Emanuel et al., 2007; Williams, 1982). Even among otherwise well-functioning family units, difficulties in communication have been shown to compromise relational dimensions of the dying experience, increasing the risk of emotional turmoil and psychological harm for all parties (King \& Quill, 2006). Moreover, problems with communication can result in lost opportunities for shared problem solving, planning for the future, and discussions regarding end-of-life preferences, all of which are important for quality care of dying people (Badr \& Taylor, 2006; Wallace, 2013).

It is evident from the literature that a variety of challenges, as well as potential rewards, can be associated with role enactment at end-of-life for dying people and their caregivers. However, more still needs to be known regarding the reasons why situations of alignment or, conversely, mismatch in role relations between dying people and those close to them might occur, as well as the way in which these mismatches go on to influence the lived experience of one or both parties. This paper aims to address these questions by examining 
the interface between the role relations among dying people and members of their social networks.

\section{Methodology}

The findings presented in this paper form part of a broader, constructivist grounded theory research project examining the process of role change at end-of-life. Grounded theory is a research methodology that involves the progressive, in-depth analysis of individual data sources with the goal of extrapolating more general explanations concerning a particular process being studied (Bryant \& Charmaz, 2010). Researchers undertaking constructivist grounded theory studies derive key concepts and subsequent theory from the research data; they also, however, acknowledge the way in which their own perspectives shape theory construction (Charmaz, 2014). Furthermore, the meanings attributed to data are recognised as being multiple rather than singular and research findings are acknowledged as having been constructed in relation to particular times, spaces, and situations (Belgrave \& Charmaz, 2014).

Constructivist grounded theory is conceptually closely aligned with symbolic interactionism. Both assert that humans construct meaning in and through their interactions within a social world (Belgrave \& Charmaz, 2014). This stance allows for the simultaneous examination of the way in which people act towards death and dying based on the meanings that these hold for them as well as how these personal meanings are constructed, modified, and reaffirmed through social interaction (Belgrave \& Charmaz, 2014; Mead, 1972). Constructivist grounded theory, therefore, recognises dying and death as being intensely personal yet fundamentally social experiences (Belgrave \& Charmaz, 2014). 
The findings outlined here relate specifically to one of the categories from the overarching study, namely "alignment and mismatch in role relations". For other published components of the study, readers are directed to Lowrie, Ray, Plummer, and Yau (2018).

\section{Sampling and Recruitment}

We adopted a purposive approach to participant recruitment using theoretical sampling to unearth rich and detailed data (Creswell, 2013; Morse, 2010). Given our interest in examining the relational nature of dying roles, we sought the perspectives of dying people as well as the perspectives of their family members and/or caregivers. Theoretical sampling in this study began quite broadly and became increasingly focused and circumscribed over time. This approach supported the development and refinement of emergent theory as the study progressed (Dey, 2010).

We raised awareness of this study through the production of an information flyer, copies of which were displayed in the regional Palliative Care Centre. Copies were also given to members of the local Palliative Care Outreach Team for distribution to individuals potentially interested in being involved in the study. Individuals were considered eligible for inclusion in the study if they had been diagnosed as having a life expectancy of six months or less, or were a family member and/or caregiver of an individual with a life expectancy of six months or less. Potential participants were regarded as ineligible for inclusion in the study if they were younger than 18 years of age, had rapidly deteriorating conditions, were identified as being within the last 48 hours of life, or had conditions or symptoms that negated their ability to participate meaningfully in an interview.

We determined the sample size based on the principle of data saturation, meaning that recruitment continued until no new variant cases arose and sufficient data had been gathered to define, check, and explain relationships between and within theoretical categories 
(Charmaz, 2014). In total, we interviewed 21 participants-13 dying people (described in the findings as P1-P13) and 8 caregivers of dying people (described as C1-C8). Two interviews were undertaken with the dying person and caregiver together and the remainder were carried out individually. Five dying person-caregiver dyads (totalling 10 participants) were present among the participant sample.

All participants were living in Australia. Twelve participants were women (5 dying people and 7 carers) and 9 were men ( 8 dying people and 1 carer). Thirteen participants identified as White Australian, 1 as Aboriginal Australian, 5 as White British, and 2 as White New Zealander. The age of participants ranged from 30 to 87 with an average of 69 for dying people and 57 for carers. Eleven participants described themselves as working class and 10 as middle class. Of the 13 dying persons, 10 had cancer diagnoses, 1 had motor neurone disease, 1 had chronic obstructive pulmonary disorder, and 1 indicated having multiple diagnoses. The time since participants had been told of their dying status ranged from 2 to 48 months with a median of 10 months. One participant did not indicate when his dying diagnosis had been received. Specific demographics details of individual participants are presented in Table 1.

\section{Data Collection and Analysis}

The first author (DL) gathered data through a series of semi-structured, open-ended interviews. An interview guide developed by the research team (all four authors of this paper) was used flexibly in steering the interviews. The interview guide was modified by the research team following preliminary data analysis (from the first three interviews) and then further modified periodically thereafter to support continued analysis and refinement of emergent theory (Charmaz, 2014). 
Interview lengths ranged from 30 to 177 minutes and averaged 88 minutes. All but one interview were conducted in participants' homes. Interviews were digitally recorded and then transcribed. NVivo Pro software ${ }^{\odot}$ (version 11) was used to assist in organising data during the analysis process. Analysis was guided broadly by a grounded theory framework as described by Glaser and Strauss $(1965 ; 1967)$. This approach, however, was modified by drawing on recommendations by Layder (1993) to accommodate observational evidence, documents, and artefacts and also by Charmaz (2014) to reflect a constructivist epistemological stance. Additionally, we used narrative inquiry as an additional analytical tool to support analysis. Narrative inquiry encourages examination of the reciprocal relationship between each participant and his or her social context, particularly in relation to experiences, milestone events, key characters, and chronology (Creswell, 2013; Thomas, 2012). The use of narrative inquiry as an analytical lens thus offered us insights into key events and milestones in participants' lives, such as symptom development and progression, receipt of a dying diagnosis, transition to palliative care, visits from friends and relatives. Additionally, narrative inquiry assisted in developing an understanding of the timeframe and sequencing of these key events; the physical, cultural, and institutional contexts in which events took place; and the way in which interactions and relations with other actors shaped various end-of-life experiences.

Analysis of transcripts commenced with open coding. This entailed DL undertaking line-by-line coding of data in order to elicit 'key incidents' from participant narratives and then comparing these to each other (Glaser \& Holton, 2004). These initial codes were discussed and revised over time in a series of meetings involving the research team. Following open coding, focused coding, involving the targeted collection and analysis of data through theoretical sampling and constant comparison, was undertaken as a means of refining 
the logic and boundaries of the theory. This process enabled the refinement and solidification of the emerging conceptual framework and testing its explanatory power (Holton, 2010).

DL maintained a research diary throughout the research process in order to note thoughts, feelings, and observations following interviews and to record emerging ideas. DL also compiled theoretical notes ('memos') during the data collection and analysis phases as a means of guiding, mapping the emergence and refining codes and subsequent theory. Diary entries and memos were routinely discussed among the research team as a means of ensuring a robust and transparent reasoning process and appropriately managing researcher perspectives and interpretations (Saldana, 2013; Snowden, 2015).

\section{Ethical Considerations}

Ethical approval for the study was received from the Townsville Hospital and Health Service Human Research Ethics Committee (approval number HREC/14/QTHS/196) and the James Cook University Human Research Ethics Committee (approval number H6101). The Participant Information Sheet and Informed Consent Form both stipulated that individuals were not obliged to participate in the study and that they had the right to withdraw, without consequence, at any stage prior to the final processing of their data. Written consent was gained prior to each interview and then revisited verbally upon interview completion (Byrne, 2001). In order to ensure confidentiality, all identifying information regarding participants and/or individuals or organisations described in their narratives was removed at the point of transcription.

\section{Findings}

Four interrelated themes were identified through analysis of the data. The first of these, 'role alignment and mismatch' is an overarching theme that juxtaposes the positive outcomes that can result from situations of alignment in role relations between dying people 
and their friends and family with the distress and harm that can stem from mismatched role relations. The remaining three themes, 'the issue of protection'; 'fear of social exclusion'; and 'unwanted focus on the dying identity' highlight a number of factors that contribute to mismatched role relations.

\section{Role Alignment and Role Mismatch}

Alignment in role relations occurred when all parties in a particular social encounter preferred and adhered to the same set of social scripts. On some occasions, this alignment involved continuity of living role relations; on other occasions it entailed extension of role relations based on the sick role and, on yet other occasions, the enactment of dying role relations. These various forms of role relations each served different purposes, such as maintenance of social (or leisure) pursuits; provision of assistance and support during periods of ill health; or advancement of practical, personal, or relational end-of-life matters. When role alignment occurred between dying people and members of their social networks, positive outcomes generally ensued, with all parties seeming satisfied with the encounters that unfolded:

"I guess all my riding buddies... what they'll often do is on a Saturday morning now they'll go for a ride... and then they'll come down to here and then we'll have coffee... So they call in and that works really well." (P10)

“... like, at one stage I couldn't do anything. I was just bed, chair, bed, chair... and [husband] never cooked. So friends came around and brought soup and things like that, which was really nice..." (P6)

In contrast to these situations of role alignment, most participants also described examples of times when mismatches in role relations occurred. These mismatches typically happened when one party sought continuity in living role relations while the other sought the 
overt acknowledgement of the dying status. Given the importance placed on relationships between the dying person and close friends or family, these mismatched role relations often resulted in considerable distress and anguish, particularly when efforts at initiating enactment of the personal and/or relational dimensions of the dying role were repeatedly blocked. P2 offered a pertinent example, highlighting the angry response she received from her children when she attempted to discuss her end-of-life wishes:

"Well, they became really abusive with me and... they said all you're doing is thinking about dying, and that's not what you should be thinking about. They got very, very upset. They missed the whole point of... please talk to the person who's dying and let them tell you how they feel, let them bring back memories. Tell them what they would like to happen, you know, in the future or to them after I die. You know, I wish that you'd do this or do that, or whatever... I'd love to be able to just talk about how I feel about my funeral arrangements and what songs I want and all this sort of thing. That's the most important thing I think families can do for a dying person.” (P2)

On some occasions, family members of the dying person reported having their attempts at discussing issues relating to dying blocked. For example, $\mathrm{C} 8$ expressed a deep sense of fear that her father would die before he felt ready and willing for her to share her thoughts and feelings with him.

"It's very, very difficult. It's been the hardest part of this whole journey, is having him not emotional and present because of things that I need him to be emotionally present for. I have a million questions to ask him... Medical questions, his wishes... I want to be able to say to him, can I buy a bunch of cards, one for my 50th birthday, one for the birth of my first child and can you write messages in them for me, Dad? I'll seal them up and write on the front... this is for your 50th, this is for your first born... It's 
lonely and it kills me that there are so many of these things that I'm not going to get, simply because me asking for it is going to kill him." (C8)

\section{The Issue of Protection}

Mismatched role relations often manifested because one party assumed (sometimes correctly) that the other wanted or needed to be shielded from emotional harm. In some circumstances, this assumption involved caregivers and family members holding back on displays of emotion out of a concern that dying persons would be worried about the sadness that their dying might cause. As a result, caregivers and/or family members felt a sense of pressure to present a strong front as a means of indicating to the dying person that they were going to be okay:

"I don't know. I don't want her to see it. It makes her worse because she hates me being hurt, and she knows it's because of her that I am hurt... So it would hurt her more to see me, because then she knows what she's leaving behind... So I don't cry a lot." (C2)

"I said to him, while we're chatting about this stuff, you know, I said I just want to clarify you don't want to see us crying or upset or anything, do you? He was just like, no, I don't, not at all... He wants to believe that us girls are going to be okay, you know..."(C8)

On other occasions, efforts at protection involved the active choice to avoid sharing thoughts and feelings regarding dying, based on the belief that the other party was not yet emotionally ready to cope with end-of-life discussions:

"It's very hard for him. I accepted it a lot faster than what he did... It was like I was talking to a brick wall... [voice breaks]... I don't think he's been ready. I mean, there are a lot of things I'd like to say but he hasn't been able to accept it. I think, you know, 
he's still young and although he's not going to find another me, I want him to be happy. If he can find another partner, that would make me so happy." (P6)

People's efforts at protecting others from the emotional burden associated with dying role relations were undertaken altruistically but often came at a profound personal cost. Many participants feared that they might miss opportunities to discuss important end-of-life matters. Others stated that they had elected to withhold their feelings, even though they felt that doing so would result in harm to themselves in the longer term:

"So I decided in my head, just pull yourself together, you've got a few weeks, and whatever emotional damage you do to yourself by not grieving properly, over this next two weeks, three weeks, whatever, you've got time after that to give yourself that care to undo that emotional damage that you might cause by not crying at the moment..." (C8)

\section{Fear of Social Exclusion}

The tendency among dying people to favour living role relations with members of their extended social networks also stemmed from a concern that a focus on dying might result in exposure, othering, and social exclusion. In many cases, the dying people interviewed seemed to be suggesting that acknowledgement of their dying status risked in some way contaminating relationships, events, and discussion. P11 indicated a belief that many of his friends had deliberately distanced themselves from him once his non-curable illness became known:

"Simple as that... your friends disappear. Very few people come in to visit you because they don't want to become involved... because you are a stigma... They don't want to know because, as I say, you're a stigma, a thorn in their sides." (P11) 
Other participants described efforts to circumvent exclusion by keeping their dying status to themselves:

\footnotetext{
"We've got a friend at the moment who's... just about to have chemotherapy. She doesn't want to see anybody. She just wants to have it, and not be exposed as vulnerable, different to what she used to. I'm a bit like that, really." (P12)
}

Some participants recounted stories in which family members, friends, or colleagues of a dying person had engaged briefly in dying role relations but had then withdrawn when the dying person remained alive for longer than expected:

"My brothers all raced up... to see her because they knew it was going to happen within that month. But since that month has been and gone, they've had very little communication." (C1)

“...we had a good friend who... was in charge of a private hospital and he got very ill, and everybody thought he was a goner there in hospital... and arrangements were made, alternative arrangements. But then he got better, the doctor came back... people have done their grieving and closed off... [there was] a lot of anger at him. Not overtly expressed but you could pick it up... He should be dead, he should have died.” (P12)

It is, perhaps, out of fear of responses such as those described here that many of the dying people interviewed suggested that they would be more prepared to discuss their dying only when it was evident that death was nearing. "So you know... you may as well go out there and enjoy yourself, and hopefully let no one know that you are dying until the right time." (P5)

\section{Unwanted Focus on the Dying Identity}


In contrast to the situations of social exclusion described above, misaligned role relations also sometimes occurred when dying persons experienced what they considered too much contact from members of their social circles, particularly if this resulted in unwanted focus upon themselves as dying individuals. On some occasions, this happened when members of the dying person's social network attempted to initiate dying role relations before the dying person wanted to do so. This often seemed be the case with members of dying people's extended social networks with whom they had only occasional contact. The mismatch appears to stem from a reliance on historical scripts for dying role enactment that were founded on the premise of there being a relatively brief duration between declaration of dying and the actual event of death. For people who see the dying person only occasionally, a focus on dying is seen as affording them the window to enact what they consider to be their small part in the dying drama (e.g., to offer condolences, forge final memories, or even to say goodbye). The emotional burden associated with this interaction is manageable for non-dying individuals because for them it is a one-off or occasional exchange. However, in the contemporary and elongated drama of dying, the dying person will experience multiple encounters of this nature, with numerous people and over long periods of time. This means that the burden is compounded for dying persons and they may, therefore, become frustrated with and/or strive to avoid such interactions:

"Yeah, they're all coming to visit [laughs]. Everyone wants to see me. In the last six months we've had visits from basically all the siblings... Mum and Dad usually come over every year but they've been over three times I think in the last six months. It's starting to get a little bit wearing, actually... It's the same with my friends. I'm getting an awful lot of visits from friends that I don't usually see quite so frequently. It just gets to me - I like my alone time. I'm not getting much of that anymore.” (P3) 
"No, but generally, I find people come out wanting to know the ins and outs of everything, how you're feeling today, where is it, and all this sort of stuff. You get fed up with that. I'm not going to talk about that anymore." (P9)

One participant expressed particular angst about the unsolicited attention he received from distant family. These family members might well have been trying to enact what they saw as their part in the drama of dying by demonstrating support for a member of their kin. Nevertheless, for the dying person, these intrusions were not welcomed:

"But then there are some people, some of my relatives, who I haven't heard from for years and years. Suddenly, I get a phone call, or now with social media, you'll get something on Facebook or something completely out of the blue, and they'll want to know how you are and what's going on... It's quite possible that they're family and they feel that that's part of the family role to contact me...Y You kind of just go, well, why do we want to have these conversations...? I don't particularly want to talk about it, particularly to someone who I haven't seen for so long who's not going to be of any help to me. I just don't understand it.” (P10)

Unwanted attempts at contact such as this were not uncommon in participants' narratives and generally seemed to be well-intended. However, the incongruence between the intentions of the individual making contact and the way in which the recipient perceived the interaction further emphasises the uncertainty that exists for many people in relation to their expected role in the contemporary drama of dying.

\section{Discussion}

In undertaking this research, we set out to examine the interface between the role relations among dying people and members of their social networks, as well as the way in which these role relations affect the lived experience of one or both parties. We found 
numerous situations described by participants of role alignment, which generally resulted in positive practical, relational, and personal outcomes. However, the dying people and their caregivers we interviewed also discussed several examples of role mismatch and highlighted the way in which these contributed to feelings of frustration, distress, and even anguish. Our analysis also identified three factors that seemed to contribute to mismatched role relations the issue of protection, fear of social exclusion, and the unwanted focus on the dying identity.

A number of important clinical and conceptual insights arise from these findings. Prior to outlining these implications, however, it is important to note that we are not asserting in this paper that there is an idealised form of role relations between dying people and those around them that should be adhered to in all circumstances. The way in which dying roles are enacted is shaped by the complex interplay of individual agency coupled with familial, social, cultural, and historical influences, meaning that a degree of diversity is inevitable (Broom \& Kirby, 2013). Moreover, the hazards associated with homogeneity in the management of dying are well documented (Broom \& Kirby, 2013; Hart, Sainsbury, \& Short, 1998; King \& Quill, 2006; McNamara, 2004). Clearly, there will be times when dying people and their loved ones have needs and wishes that do not align. Nevertheless, conflict, confusion, or divisions that occur between dying people and those around them due to misplaced assumptions and expectations concerning the enactment of dying roles are mostly unhelpful and often avoidable. The stark difference found in our study between the positive outcomes that arose in situations where role alignment occurred, compared to the missed opportunities, frustration, and distress that manifested in instances of role mismatch, highlights this point.

Our finding in relation to the way in which altruistically intended efforts at protection can compromise role alignment points to the importance of honest, but also considered, communication at end-of-life. Previous papers have highlighted the way in which fear of upsetting loved ones can result in individuals hiding their thoughts and feelings, often at a 
personal cost to themselves (Keeley, 2016; Zhang \& Siminoff, 2003). Indeed, without quality end-of-life communication, opportunities for affirmation and closure of relationships, validation of beliefs, and reconciliation may be lost, potentially resulting in emotional exhaustion, depression, regret, and difficulties with grief (Bachner \& Carmel, 2009; Keeley, 2007; Weiner \& Roth, 2006). Research also indicates, however, that not all communication among dying persons and their families at end-of-life is helpful. Scott and Caughlin (2014) argue that communication quality, rather than quantity, is key at end-of-life and that blanket openness can often be harmful. Our research findings add to this perspective by highlighting that, unless alignment exists between parties in relation to the specific goals of end-of-life conversations, the communication encounter is unlikely to be successful. Moreover, given that different actors' preferences in relation to role relations vary over time, the point of focus and approach to communication may need to be both flexible and tentative in response.

The concerns expressed by some participants regarding the possibility (or actuality) of social exclusion resulting from their dying status becoming known, resonate with a belief that death and dying remain a source of stigma in some social situations (Kellehear, 2007). Participants' experiences and/or fears of being avoided due to their dying status appear reflective of an early and, to some extent, gradual form of social death. Within the context of healthcare, the concept of social death is generally used to describe a loss of identity and social connectedness, as well as bodily disintegration experienced by ill or dying persons prior to the event of their actual biological death (Borgstrom, 2017; Králová, 2015). This loss of identity and connectedness can hamper the enactment of important interpersonal dimensions of end-of-life roles and compromise the ability of the dying person to negotiate dying role relations (Borgstrom, 2017).

It is important to note here, however, that although a number of the dying persons in our study reported feelings and/or fears of exclusion, we did not seek the perspectives of the 
individuals who the dying person suggested either had withdrawn or may withdraw from them. As such, we have not examined whether these individuals had knowingly withdrawn from the dying person and, if this was the case, why they had done so. Regardless, the actual or perceived withdrawal of some members of the dying person's social circle was a source of frustration and, in some instances, distress for the dying individual. Curiously, however, our study also identified situations in which dying persons felt frustrated with what they perceived as too much contact from some members of their social circles, particularly when this contact focussed on their dying status. This leaves members of a dying person's social circle in the unenviable position of not knowing if, when, and how often they ought to maintain contact with the dying individual. Future research, drawing specifically on the views and experiences of friends, families, and acquaintances of dying people, may help in shedding light on this important aspect of end-of-life role relations.

Taken collectively, our findings highlight the potential for confusion and misalignment in end-of-life role relations, resulting from a lack of clarity and associated uncertainty regarding role expectations at any given time. Recent research has indicated that the contemporary drama of dying often plays out over a longer timeframe than in historical times and, in response to this, dying persons periodically transition into and out of the living and dying selfhood (Breen, Aoun, O'Connor, Howting, \& Halkett, 2018; Kellehear, 2009; Lowrie et al., 2018). Our research suggests that, to some extent, contemporary social scripts to guide dying role relations have not yet evolved to reflect this longer and more variable drama of dying. The challenge in addressing this issue lies in the fact that clarity concerning role expectations may be neither achievable nor appropriate, as it is flexibility and adaptability that are, instead, often required. Therefore, from a clinical perspective, there well may be value in working with dying people and their family and friends in foreshadowing the potential for mismatched role relations and highlighting that different forms of these role 
relations might be sought at different times. If successful, this approach has the potential to promote opportunities for greater role alignment and, in turn, improved relational outcomes as the drama of dying unfolds.

\section{Limitations}

Although all interviews in this study were undertaken with people who had been identified as having a prognosis of less than six months (or with their caregivers), for ethical reasons we did not interview anyone thought to be in the final few days of life. This means that the insights we offer regarding role alignment and mismatch may not apply readily to late-stage dying. Interviewing family and/or caregivers after the death of their loved one may also offer some insights into role relations during the final scenes of life, but would need to account for the fact that the perspectives of dying people themselves would be obscured. Furthermore, although we set out to examine the interface in role relations between dying people and members of their social networks, our sample is entirely limited to dying people and their close caregivers. This means that some of the views shared regarding role relations between dying people and their social circle are rather one-sided. Further research to examine the viewpoints of members of dying person's outer social circles would add an additional and important dimension to research of this nature. Finally, although our research drew on the perspectives of 21 individuals, we do not claim that the experiences that they shared are representative of those of all dying people. Only three of the dying persons interviewed were aged younger than 50 and our recruitment process limited our study to individuals experiencing illness related dying. A broader sample may have added to the generalisability of our findings.

\section{Conclusion}


In this paper, we have examined role relations at end-of-life. We identified that role alignment often leads to very positive relational and practical outcomes, whereas role mismatch can be a significant and ongoing source of distress for dying people as well as for their family and/or caregivers. We have highlighted a number of factors that contribute to role mismatch between dying people and members of their social circle, including efforts to shield each other from emotional harm; fears of social exclusion; and unwanted focus on the dying identity. Finally, we have argued that recognition of the need for flexible and adaptable dying role relations may support role alignment between dying people and those who matter to them. 


\section{References}

Aoun, S. M., Kristjanson, L. J., Currow, D. C., \& Hudson, P. L. (2005). Caregiving for the terminally ill: at what cost? Palliative Medicine, 19(7), 551-555. doi:10.1191/0269216305pm1053oa

Bachner, Y. G., \& Carmel, S. (2009). Open communication between caregivers and terminally ill cancer patients: The role of caregivers' characteristics and situational variables. Health Communication, 24(6), 524-531. doi:10.1080/10410230903104913

Badr, H., \& Taylor, C. L. C. (2006). Social constraints and spousal communication in lung cancer. Psycho-Oncology, 15(8), 673-683. doi:10.1002/pon.996

Belgrave, L. L., \& Charmaz, K. (2014). Studying illness and dying through constructivist grounded theory. In L. Van Brussel \& N. Carpentier (Eds.), The Social Construciton of Death. Interdisciplinary Perspectives. (pp. 34-52). London: Palgrave Macmillan.

Biddle, B. J. (1986). Recent developments in role theory. Annual Review of Sociology, 12(1), 67-92. doi:10.1146/annurev.soc.12.1.67

Borgstrom, E. (2017). Social death. QJM, 110(1), 5-7. doi:10.1093/qjmed/hcw183

Breen, L. J., Aoun, S. M., O'Connor, M., Howting, D., \& Halkett, G. K. B. (2018). Family caregivers' preparations for death: A Qualitative Analysis. Journal of Pain and Symptom Management, 55(6), 1473-1479. doi:10.1016/j.jpainsymman.2018.02.018

Broom, A., \& Kirby, E. (2013). The end of life and the family: hospice patients' views on dying as relational. Sociology of Health and Illness, 35(4), 499-513. doi:10.1111/j.14679566.2012.01497.x

Bryant, A., \& Charmaz, K. (2010). The SAGE handbook of grounded theory (Pbk. ed.). Los Angeles: Sage.

Burns, C. M., Abernethy, A. P., Leblanc, T. W., \& Currow, D. C. (2011). What is the role of friends when contributing care at the end of life? Findings from an Australian population study. Psycho-Oncology, 20(2), 203-212. doi:10.1002/pon.1725

Byrne, M. (2001). The concept of informed consent in qualitative research. AORN journal, 74(3), 401-403. doi:10.1016/S0001-2092(06)61798-5

Charmaz, K. (2014). Constructing grounded theory (2nd ed.). London: Sage.

Clemmer, S. J., Ward-Griffin, C., \& Forbes, D. (2008). Family members providing home-based palliative care to older adults: the enactment of multiple roles. Canadian Journal on Aging, 27(3), 267-283.

Creswell, J. W. (2013). Qualitative inquiry and research design: choosing among five approaches (3rd ed.). Thousand Oaks, CA: Sage.

Dey, I. (2010). Grounding categories. In A. Bryant \& K. Charmaz (Eds.), The SAGE handbook of grounded theory (pp. 167-190). Los Angeles: Sage.

Emanuel, L., Bennett, K., \& Richardson, V. E. (2007). The dying role. Journal of Palliative Medicine, 10(1), 159-168. doi:10.1089/jpm.2006.0134

Glaser, B. G., \& Holton, J. A. (2004). Remodeling grounded theory. Forum Qualitative Sozialforschung, 5(2).

Glaser, B. G., \& Strauss, A. L. (1965). Awareness of dying. Chicago: Aldine Transaction.

Glaser, B. G., \& Strauss, A. L. (1967). The discovery of grounded theory: Strategies for qualitative research. New York: Aldine Pub. Co.

Hart, B., Sainsbury, P., \& Short, S. (1998). Whose dying? A sociological critique of the 'good death'. Mortality, 3(1), 65-77. doi:10.1080/713685884

Holton, J. A. (2010). The coding process and its challenges. In A. Bryant \& K. Charmaz (Eds.), The $S A G E$ handbook of grounded theory (pp. 265-289). Los Angeles: Sage.

Hudson, P., \& Payne, S. (2011). Family caregivers and palliative care: Current status and agenda for the future. Journal of Palliative Medicine, 14(7), 864-869. doi:10.1089/jpm.2010.0413

Keeley, M. P. (2007). Turning toward death together': The functions of messages during final conversations in close relationships. Journal of Social and Personal Relationships, 24(2), 225-253. doi:10.1177/0265407507075412 
Keeley, M. P. (2016). Family communication at the end of life. Journal of Family Communication, 16(3), 189-197. doi:10.1080/15267431.2016.1181070

Kellehear, A. (2007). A social history of dying. New York: Cambridge University Press.

Kellehear, A. (2008). Dying as a social relationship: A sociological review of debates on the determination of death. Social Science \& Medicine, 66(7), 1533-1544. doi:10.1016/j.socscimed.2007.12.023

Kellehear, A. (2009). The study of dying. From autonomy to transformation. Cambridge: Cambridge University Press.

King, D. A., \& Quill, T. (2006). Working with families in palliative care: One size does not fit all. Journal of Palliative Medicine, 9(3), 704-715. doi:10.1089/jpm.2006.9.704

Kirby, E., Broom, A., Good, P., Wootton, J., \& Adams, J. (2014). Families and the transition to specialist palliative care. Mortality, 19(4), 323-341. doi:10.1080/13576275.2014.916258

Králová, J. (2015). What is social death? Contemporary Social Science, 10(3), 235-248. doi:10.1080/21582041.2015.1114407

Laryionava, K., Pfeil, T. A., Dietrich, M., Reiter-Theil, S., Hiddemann, W., \& Winkler, E. C. (2018). The second patient? Family members of cancer patients and their role in end-of-life decision making. BMC Palliative Care, 17(29), 1-9. doi:10.1186/s12904-018-0288-2

Layder, D. (1993). New strategies in social research: An introduction and guide. Cambridge, U.K: Polity Press.

Lowrie, D., Ray, R., Plummer, D., \& Yau, M. (2018). Examining the transitions between living and dying roles at end-of-life. Death Studies, 1-10. doi:10.1080/07481187.2018.1504836

Lynch, K. D. (2007). Modeling role enactment: Linking role theory and social cognition. Journal for the Theory of Social Behaviour, 37(4), 379-399. doi:10.1111/j.1468-5914.2007.00349.x

McNamara, B. (2004). Good enough death: autonomy and choice in Australian palliative care. Social Science \& Medicine, 58(5), 929-938. doi:10.1016/j.socscimed.2003.10.042

Mead, G. H. (1972). Mind, self, and society from the standpoint of a social behaviorist. Chicago: University of Chicago Press.

Morse, J. M. (2010). Sampling in grounded theory. In A. Bryant \& K. Charmaz (Eds.), The SAGE handbook of grounded theory (pp. 229-244). Los Angeles: Sage.

Pleschberger, S., \& Wosko, P. (2017). From neighbour to carer: An exploratory study on the role of non-kin-carers in end-of-life care at home for older people living alone. Palliative Medicine, 31(6), 559-565. doi:10.1177/0269216316666785

Saldana, J. (2013). The coding manual for qualitative researchers (2nd ed.). London: Sage.

Scarre, G. (2009). Dying and philosophy. In A. Kellehear (Ed.), The study of dying. From autonomy to transformation. (pp. 147-162). Cambridge: Cambridge University Press.

Scott, A. M., \& Caughlin, J. P. (2014). Enacted goal attention in family conversations about end-oflife health decisions. Communication Monographs, 81(3), 261-284. doi:10.1080/03637751.2014.925568

Snowden, M. (2015). Use of diaries in research. Nursing Standard, 29(44), 36-41. doi:10.7748/ns.29.44.36.e9251

Stone, A. M., Mikucki-Enyart, S., Middleton, A., Caughlin, J. P., \& Brown, L. E. (2012). Caring for a parent with lung cancer: Caregivers' perspectives on the role of communication. Qualitative Health Research, 22(7), 957-970. doi:10.1177/1049732312443428

Thomas, S. (2012). Narrative inquiry: embracing the possibilities. Qualitative Research Journal, 12(2), 206-221. doi:10.1108/14439881211248356

Wallace, C. L. (2013). Family communication and decision making at the end of life: A literature review. Palliative and Supportive Care, 13(3), 815-825. doi:10.1017/S1478951514000388

Weiner, J. S., \& Roth, J. (2006). Avoiding iatrogenic harm to patient and family while discussing goals of care near the end of life. Journal of Palliative Medicine, 9(2), 451-463. doi:10.1089/jpm.2006.9.451

Williams, C. A. (1982). Role Considerations in Care of the Dying Patient: What is the professional role in caring for the dying? Image, 14(1), 8-11. doi:10.1111/j.1547-5069.1982.tb01496.x

Zhang, A. Y., \& Siminoff, L. A. (2003). Silence and cancer: Why do families and patients fail to communicate? Health Communication, 15(4), 415-429. doi:10.1207/S15327027HC1504_03 
Table 1 - Demographic details of study participants

\begin{tabular}{|c|c|c|c|c|c|c|c|c|}
\hline Code & Status & Dyad? & Gender & Age & Cultural background & Religion & Diagnosis & $\begin{array}{c}\text { Time since receiving the news } \\
\text { that diagnosis was terminal } \\
\text { (Approximate only) }\end{array}$ \\
\hline P1 & Dying person & $\mathrm{N}$ & $\mathrm{M}$ & $80-90$ & Scottish Australian & Catholic & Metastatic stomach cancer & 4 months \\
\hline $\mathrm{P} 2$ & Dying person & $\mathrm{N}$ & $\mathrm{F}$ & $70-80$ & White Australian & Atheist & Pancreatic cancer & 22 months \\
\hline P3 & Dying person & $\mathrm{N}$ & $\mathrm{F}$ & $40-50$ & White Australian & Christian & Metastatic stomach cancer & 6 months \\
\hline P4 & Dying person & $\mathrm{Y}(\mathrm{C} 1)$ & $\mathrm{F}$ & $70-80$ & White Australian & None & Metastatic breast cancer & 4 months \\
\hline P5 & Dying person & $\mathrm{N}$ & $\mathrm{M}$ & $60-70$ & White Australian & Christian & Metastatic prostate cancer & 24 months \\
\hline P6 & Dying person & $\mathrm{N}$ & $\mathrm{F}$ & $40-50$ & New Zealander & Baptist & Vaginal cancer & 16 months \\
\hline P7 & Dying person & $\mathrm{N}$ & $\mathrm{M}$ & $60-70$ & New Zealander & Catholic & Metastatic lung cancer & 2 months \\
\hline P8 & Dying person & $\mathrm{Y}(\mathrm{C} 2)$ & $\mathrm{F}$ & $60-70$ & White Australian & Christian & Metastatic breast cancer & 48 months \\
\hline P9 & Dying person & $\mathrm{Y}(\mathrm{C} 3)$ & $\mathrm{M}$ & $70-80$ & English (63 years in Australia) & Christian & Oesophageal cancer & 6 months \\
\hline P10 & Dying person & $\mathrm{Y}(\mathrm{C} 4)$ & $\mathrm{M}$ & $60-70$ & White Australian & Catholic & Metastatic lung cancer & 14 months \\
\hline P11 & Dying person & $\mathrm{N}$ & $\mathrm{M}$ & $70-80$ & White British & Catholic & MND & 23 months \\
\hline P12 & Dying person & $\mathrm{Y}(\mathrm{C} 5)$ & $\mathrm{M}$ & $80-90$ & British (16 years in Australia) & None & COPD & 6 months (estimate) \\
\hline P13 & Dying person & $\mathrm{N}$ & $\mathrm{M}$ & $80-90$ & White Australian & None & Multiple diagnoses & Not stated \\
\hline $\mathrm{C} 1$ & Carer (for mother) & $\mathrm{Y}(\mathrm{P} 4)$ & $\mathrm{F}$ & $40-50$ & White Australian & None & Metastatic breast cancer (mother) & 4 months \\
\hline $\mathrm{C} 2$ & Carer (for mother) & $\mathrm{Y}(\mathrm{P} 8)$ & $\mathrm{F}$ & $30-40$ & White Australian & None & Metastatic breast cancer (mother) & 48 months \\
\hline $\mathrm{C} 3$ & Carer (spouse) & $\mathrm{Y}(\mathrm{P} 9)$ & $\mathrm{F}$ & $70-80$ & White Australian & Christian & Oesophageal cancer (husband) & 6 months \\
\hline $\mathrm{C} 4$ & Carer (spouse) & $\mathrm{Y}(\mathrm{P} 10)$ & $\mathrm{F}$ & $50-60$ & White Australian & Catholic & Metastatic lung cancer (husband) & 14 months \\
\hline $\mathrm{C} 5$ & Carer (spouse) & $\mathrm{Y}(\mathrm{P} 12)$ & $\mathrm{F}$ & $80-90$ & British (16 years in Australia) & None & COPD (husband) & 6 months (estimate) \\
\hline C6 & Carer (spouse) & $\mathrm{N}$ & $\mathrm{M}$ & $50-60$ & Aboriginal Australian & Catholic & MND (wife) & 60 months (estimate) \\
\hline $\mathrm{C} 7$ & Carer (spouse) & $\mathrm{N}$ & F & $60-70$ & White Australian & Anglican & Bowel cancer (husband) & 66 months \\
\hline $\mathrm{C} 8$ & Carer (for Father) & $\mathrm{N}$ & $\mathrm{F}$ & $30-40$ & Italian Australian & Atheist & Metastatic lung cancer (father) & 40 months \\
\hline
\end{tabular}

